\title{
Research on The Springback Offset Based on MLS-SA
}

\author{
Zhaohu Deng ${ }^{1,2, a}$ \\ ${ }^{1}$ School of Mechanical and Automotive Engineering South China University of Technology \\ Guangzhou, China \\ ${ }^{2}$ Mechanical and Electrical Engineering Department Guangdong Polytechnic College Guangzhou, \\ China \\ a360596374@qq.com
}

Keywords: springback; mould surface modification; response surface method; optimization Abstract. Springback is a kind of typical defect in sheet metal punching. Although it could be resolved with mould surface modification, it is inefficient with traditional method. In this paper, a new method of mould surface modification was proposed. The new method converted the traditional method into an optimization problem. And then the mapping model and the optimization method would be studied further. Finally the proposed method was applied for springback offset. And the results showed that the method could resolve the springback offset issue effectively.

\section{Introduction}

During the course of sheet metal manufacture, the punched workpiece will deform opposite to the forming direction. This phenomenon is so called springback [1]. The springback always causes the shape error. When it is serious, the workpiece may not be used normally. So how to decrease the springback has always been a focus in the field of sheet metal punching. Researches showed that the springback could be decreased but not to be eliminated. So springback offset was the important method presently [2]. This method would modify the mould surface opposite to the direction of springback. Thus when the workpiece took place springback, it could just deform to the right shape. That meant the springback was compensated.Fig. 1 illustrates the theory of springback offset. However the course of springback is very complicated. It is hard to define the extent of modification. So it is meaningful to find a way which could help to decide the offset value when modifying the mould surface.

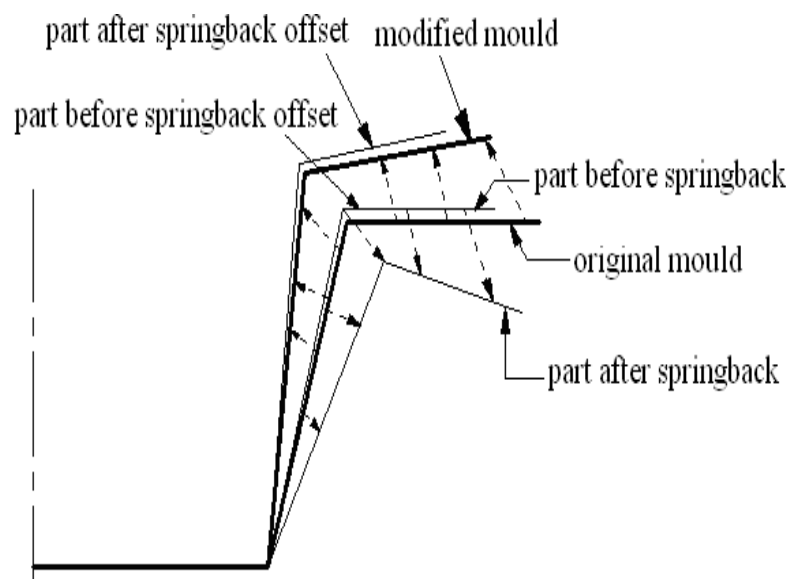

Fig 1. The theory of springback offset

\section{The theory of springback offset}

Mould surface modification is a kind of method that needed to move the mould surface to some place in the opposite direction of springback. For example there was a mould, its shape was defined as $\mathrm{U}_{\mathrm{m}}{ }^{1}(\mathrm{x})$. Here the shape of mould surface $U_{m}{ }^{1}(x)$ was equal to the shape of ideal workpiece $U_{0}$. Because of the springback, the shape of the workpiece after punching could be defined as Eq. 1.

$$
U_{p}^{1}(x)=U_{m}^{1}(x)+U_{s}^{1}(x)
$$


In Eq. 1, $\mathrm{U}_{\mathrm{s}}{ }^{1}(\mathrm{x})$ was the increment caused by springback. So it should take a springback offset to eliminate this increment. Then the shape of modified mould could be defined as Eq. 2.

$U_{m}^{2}(x)=U_{m}^{1}(x)-U_{s}^{1}(x)$

After mould modification, the shape of the workpiece punched with modified mould was defined as Eq. 3.

$U_{p}^{2}(x)=U_{m}^{2}(x)+U_{s}^{2}(x)$

Substituted Eq. 2 withEq. 3, it could get Eq. 4.

$U_{p}^{2}(x)=U_{m}^{1}(x)-U_{s}^{1}(x)+U_{s}^{2}(x)$

It presumed that the shape of the workpiece punched with modified mould was just equal to the shape of ideal workpiece, then $\mathrm{U}_{\mathrm{p}}^{2}(\mathrm{x})=\mathrm{U}_{0}$, Eq. 5 could be calculated by Eq. 4 .

$-U_{s}^{1}(x)+U_{s}^{2}(x)=0$

It can be seen that only when $U_{\mathrm{s}}^{1}(\mathrm{x})=U_{\mathrm{s}}^{2}(\mathrm{x})$ it could get the ideal workpiece. But in most cases

$U_{\mathrm{s}}^{1}(\mathrm{x}) \neq U_{\mathrm{s}}^{2}(\mathrm{x})$, so it should bring a factor $\alpha$ which can make $\alpha U_{\mathrm{s}}^{1}(\mathrm{x})=U_{\mathrm{s}}^{2}(\mathrm{x})$. The factor $\alpha$ can be modified according to the deviation between the real results and the prediction. Usually it was accomplished depending on the field experience. The whole springback offset was an iterative process. And it would cost much time. So it proposed a new method of mould surface modification to replace the factor definition.

\section{Research on the modifying mould surface}

The Theory of Mould Surface Modification. The springback of sheet metal is also a kind of metal formation. So it conforms to the metal forming rule. And there must be a mapping relationship which could reflect the shape change before and after the springback. So it proposed to build this mapping relationship with RSM (response surface method, RSM) in this paper. As it is known, the shape of workpiece before springback is equal to the shape of mould surface. So the mapping relationship built could be regard as that between the shape of mould surface and the shape of workpiece after springback. Furthermore it could build a relationship between the shape of mould surface and the shape difference of workpiece before and after springback. Thus it could modify the shape of mould surface continually with an optimization method until the difference is accepted. So it can be seen that the springback offset included two stages. One is to build a mapping model; the other is to optimize the model. In this paper it studied on them respectively.

Research on the model building. Response surface method could take an integral fitting for the datum when their mapping relationship is unknown. It could build the mapping relationship between the design variable and target function with an appropriate regression function. According to this, it has been widely applied to resolve the nonlinear problem of model building. For example Yucheng Tang resolved the problem of forging die optimization with response surface method (RSM) [3]. Jun Zhang accomplished the springback offset of car front fender based on sequential response surface method [4]. In this paper it would build a mapping model between the modified mould and its effect with RSM.

Least square method is the most common method in RSM. It emphasizes the global fitting, and it always takes the entire datum into account when fitting. Thus it could not fit the mapping relationship effectively when the datum varied dramatically in local range. Especially for the springback, it involves the high nonlinearity. It is hard to build the mapping model with least square method. So it proposed to map the relationship with another method, moving least square method (MLS). MLS emphasizes the local fitting. It mainly concerns about how the datum in local range influences the function. So MLS could reflect the local mapping relationship accurately.

For comparison, it picked up a test function as Eq. 6 shown to fit with MLS. At the same time it took least square method to fit the test function either. The variables of test function were defined as $\mathrm{W}\{-2 \leq \mathrm{x} \leq 2,-2 \leq \mathrm{y} \leq 2\}$.

$\mathrm{F}=3 \times(1-\mathrm{x})^{2} \times \exp \left(-\left(\mathrm{x}^{2}\right)-(\mathrm{y}+1)^{2}\right)-10 \times\left(\mathrm{x} / 5-\mathrm{x}^{3}-\mathrm{y}^{3}\right) \times \ldots \exp \left(-\mathrm{x}^{2}-\mathrm{y}^{2}\right)-1 / 3 \times \exp \left(-(\mathrm{x}+1)^{2}-\mathrm{y}^{2}\right)$

In the range of $\mathrm{W}$, it picked up 40 sets of datum. Fig. 2 shows the fitting result with MLS. Fig. 3 shows the fitting result with least square method. Comparing the two results, it can be seen that the 
property of MLS was superior to that of least square method. And it also took a comparison between the original model and the model built with MLS. The results showed that the maximum relative error is fewer than $5 \%$. It is precise enough for the requirement.

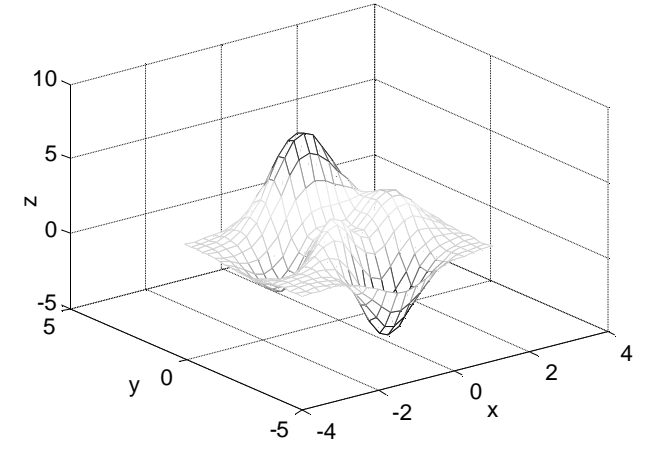

Fig 2. The RSM model based on MLS

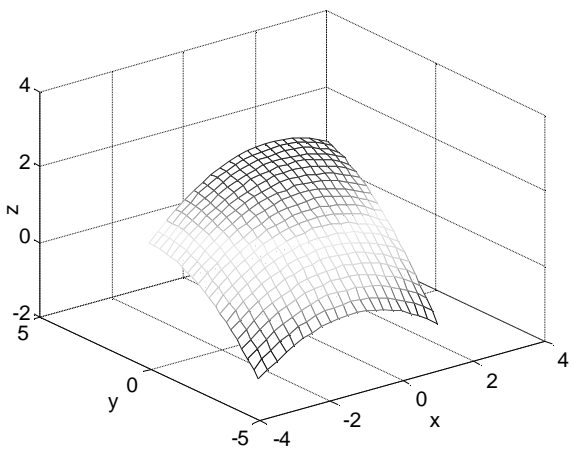

Fig 3. The traditional RSM model

Research on the optimization. In this paper the target function value of mapping model represented the similarity between the workpiece punched and the ideal workpiece. Its optimum corresponded with the desired mould surface. So it could get the desired mould surface by optimizing the mapping model. In this paper the mapping model was built with MLS. But it was a black-box model. So in this paper it proposed to use the simulated annealing algorithm (SA) to optimize the model.

The simulated annealing algorithm has the characteristic of global optimization. It can optimize the multi-dimensional and multi-modal function. But when searching the best value in local region, it will cost much time with SA [5]. So a hybrid optimal algorithm PSA based on the SA and the Powell algorithm (PA) is proposed. The PSA algorithm is a synthesis of the best characteristics of the Powell method and the SA method. It possesses the advantages of fast convergence and ability for a global minimum.

Even so, when using the typical Powell algorithm, it always leads to the problem of linear correlation. For avoiding that, when using Powell algorithm the generation of searching direction would observe the law of nearest conjugate search in this paper.

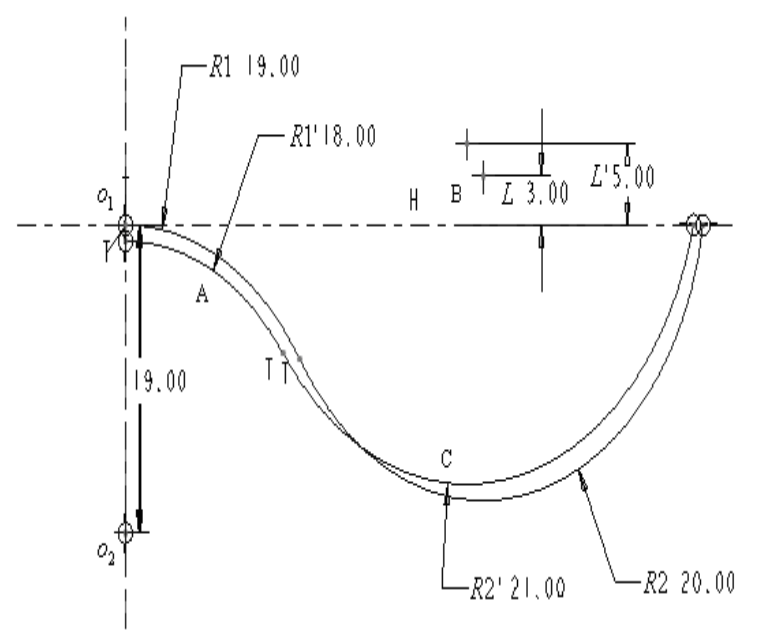

Fig4. The scheme diagram of mould surface

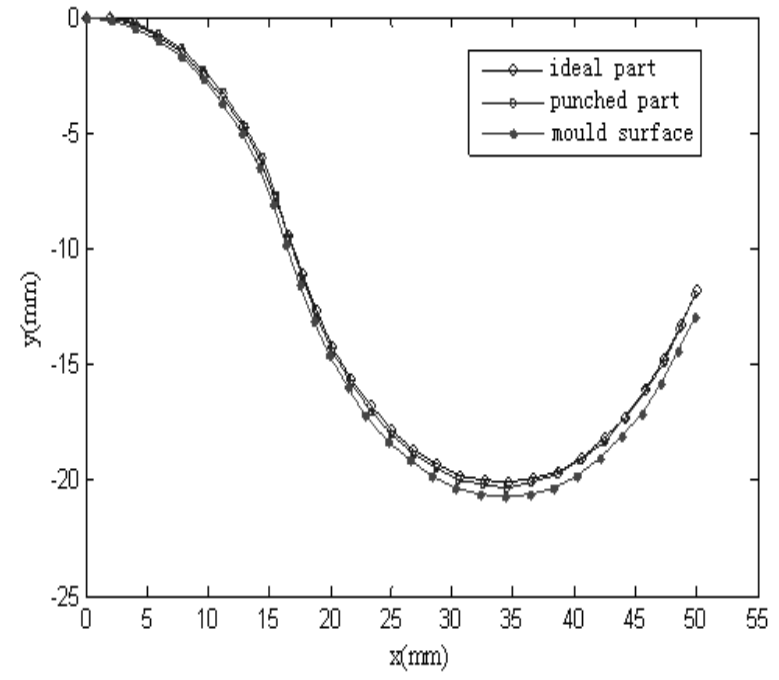

Fig 5. The comparison results

\section{Application}

In this paper it will resolve the springback problem with MLS-SA. Fig.4 is a schematic diagram of mould surface. It can be seen that the shape of mould is decided by R1, R2 and L. So it took the three parameters as design variable in this paper.For a product punched, whether its shape meeting the precise requirement or not is a judgment standard. So it took the difference between the product punched and the ideal product as the target function. In this paper it would pick up several nodes from the cross section of product, and defined the target function as Eq. 7. 


$$
d_{t}=\sum_{i=1}^{N} d_{i} \quad d_{i}=\sqrt{\left(x_{i}-X_{i}\right)^{2}+\left(y_{i}-Y_{i}\right)^{2}}
$$

In the equation, $\mathrm{N}$ is the number of nodes; $\left(\mathrm{x}_{\mathrm{i}}, \mathrm{y}_{\mathrm{i}}\right)$-is the coordinate of node at punched product, $\left(\mathrm{X}_{\mathrm{i}}, \mathrm{Y}_{\mathrm{i}}\right)$ is the coordinate of node at ideal product.

In this paper the choice of samples was based on the method of Box-Behnken design. It took the simulation for each sample with the software Dynaform. For each sample it picked up 30 corresponding nodes from the cross section of the punched product and the ideal product respectively, and calculated the target function value with Eq.7.

After building the mapping relationship with MLS, it optimized the model with PSA. After 140 iterations it obtained the optimal shape of mould surface. The parameters were defined as $\mathrm{R} 1=18.2$, $\mathrm{R} 2=20.52, \mathrm{~L}=0.75$. Then it took a springback simulation with the optimal parameters. Fig. 5 shows the results. It can be seen that the maximum relative error was at the end of semi-finished product, it was fewer than $7 \%$. So it can be granted that the product met the precise requirement after springback offset. It proved the feasibility of MLS-SA.

\section{Conclusions}

Mould surface modification is a kind of common method for springback offset. In this paper it converted it to a problem related to optimization. Then it proposed a new method MLS-SA to accomplish the springback offset. The results showed that it could get the qualified product with the method proposed in this paper.

\section{Acknowledgements}

This work was financially supported by the Project of Research and Production Combination Financed by Guangzhou. Project number: 201392-00084.

\section{References}

[1] Xiangan Yang, Feng Ruan,Chi Zhou.Multi-Objective Optimization of Forming Process of Sheet Metal Based on Springback Control [J].Journal of South China University of Technology(Natural Science Edition),2010,Vol.38(12),pp.7-12

[2] Yanping Li, Dongbo Li, Bingheng Lu.A Compensation Algorithm and Its Experimental Validation for Springback in Sheet Metal Forming [J]. Automotive Engineering,2005,vol.4(27),pp.486-491

[3] Yucheng Tang, Xionghui Zhou, Jun Chen.The Optimum Preform Design and Redesign Based on Neural Network Response Surface Methodology [J]. Journal of Shanghai Jiaotong University, 2007, vol.41(4),pp.624-628

[4] Jun Zhang, Yinlin Ke.A Research on the Optimization of Auto Panel Forming Process With Sequential Response Surface Method [J]. Automotive Engineering,2005,vol.27(2),pp.246-250

[5] Ming Zhong,Cunhao Fang, Pengwei Tian, etl. Component Retrieval Method Based on Simulated Annealing Algorithm [J].Computer Engineering,2010,vol.36(16) ,pp.13-15 